\title{
Thyroid function tests in chronic liver disease: evidence for multiple abnormalities despite clinical euthyroidism
}

\author{
M BORZIO, R CALDARA, F BORZIO, V PIEPOLI, P RAMPINI, AND C FERRARI
}

From the Second Department of Medicine, Fatebenefratelli Hospital, Milan, Italy

SUMmaRY To further evaluate thyroid function in patients with liver disease, we have measured total and free $T_{3}$ and $T_{4}$, thyroxine binding globulin, basal and thyrotropin releasing hormone-stimulated thyrotropin and thyroglobulin antibodies in 33 patients with liver cirrhosis, in 22 with chronic hepatitis and in $\mathbf{3 0}$ healthy controls. All the patients but one were clinically euthyroid. $\mathrm{T}_{3}, \mathrm{FT}_{3}, \mathrm{~T}_{3}$ /thyroxine binding globulin and $\mathrm{T}_{4} /$ thyroxine binding globulin ratios and thyrotropin after thyrotropin releasing hormone were significantly reduced, while $\mathrm{FT}_{4}$, thyroxine binding globulin and thyrotropin were significantly increased in liver cirrhosis. In chronic hepatitis group, $\mathrm{FT}_{3}$ and $\mathrm{T}_{3}$ /thyroxine binding globulin ratio were significantly lower and thyroxine binding globulin and $\mathrm{FT}_{4}$ were higher than in healthy controls. The between patients comparison revealed a significantly lower $\mathrm{T}_{3}, \mathrm{FT}_{3}, \mathrm{~T}_{3} /$ thyroxine binding globulin and $\mathrm{T}_{4} /$ thyroxine binding globulin ratios and $\Delta$ thyrotropin in cirrhotics. Thyroglobulin antibodies were present at high titre only in two patients one of whom having evidence of Hashimoto's thyroiditis with subclinical hypothyroidism. The correlation coefficient between $T_{4}$ /thyroxine binding globulin ratio and $\mathrm{FT}_{4}$ were lower in patients than in controls. Furthermore an abnormal thyrotropin response to thyrotropin releasing hormone was shown in 10 cirrhotics and in four patients with chronic hepatitis. Serum $\mathrm{T}_{3}$ significantly correlated with serum bilirubin, albumin, and prothrombin time in both groups of patients. The present data confirm the existence of several abnormalities of thyroid function tests in patients with chronic liver disease, although showing that euthyroidism is almost always maintained, probably as a result of low-normal $\mathrm{FT}_{3}$ and high-normal $\mathrm{FT}_{4}$. Furthermore, $\mathrm{T}_{3}$ serum levels appear to parallel the severity of liver dysfunction.

The liver plays an important role in thyroid hormone metabolism being involved in their conjugation, excretion, peripheral deiodination and in synthesis of thyroxine binding globulin. Although almost all patients with liver disease are clinically euthyroid, some abnormalities in circulating hormone concentrations have been shown in previous studies. ${ }^{1-4}$ These data, however, are still controversial as the discrepant results reported may depend on the different analytical methods used as well as the different groups of patients investigated. In fact, total and free thyroxine $\left(\mathrm{T}_{4}\right.$ and $\left.\mathrm{FT}_{4}\right)$ serum concentrations have been reported as normal, increased or decreased in various liver diseases; $;^{3-7}$ abnormalities in thyroxine binding globulin serum

\footnotetext{
Address for correspondence and reprints: Dr M Borzio, II Department of Medicine, Fatebenefratelli Hospital, C.so di Porta Nuova, 23, 20121 Milano, Italy.

Received for publication 21 September 1982
}

concentration and a reduced thyroid hormone binding capacity, perhaps because of a hypothetical circulating inhibitor, have been also reported. ${ }^{8}$ Moreover, total and free triiodothyronine $\left(\mathrm{T}_{3}\right.$ and $\mathrm{FT}_{3}$ ) concentrations are often decreased, sometimes profoundly and their levels correlate well with the severity of liver dysfunction. ${ }^{4-9}$ In order to further evaluate thyroid function in liver disease, we have measured $T_{3}, T_{4}, F T_{3}, F_{4}$ serum levels, thyroxine binding globulin, thyrotropin both in basal conditions and after thyrotropin releasing hormone administration, and thyroglobulin antibodies in a large number of patients with chronic liver diseases.

\section{Methods}

SUBJECTS

Fifty five patients, 44 men and 11 women, with chronic liver disease, aged 27-72 years, have been 
studied. They were divided in two different groups: patients with advanced liver cirrhosis and patients with chronic hepatitis.

\section{LIVER CIRRHOSIS}

This group included 33 patients (29 men and four women) aged 45-72 years. All of these subjects were hospitalised because of signs and symptoms of decompensated liver cirrhosis. None of them had evidence of oesophago-gastric bleeding, acute hepatic encephalopathy, or renal failure. Owing to either clinical conditions or coagulation abnormalities, liver biopsy was not performed in any of our cirrhotics.

\section{CHRONIC HEPATITIS}

This group included 22 subjects $(15$ men and seven women) aged 27-56 years. The diagnosis of chronic hepatitis was made in all cases by needle biopsy according to the criteria of an international group. ${ }^{10}$ None of these patients showed evidence of nodular evolution in their liver specimen, although it is possible that needle biopsies in these patients may underestimate the number that have progressed to cirrhosis.

The data on histological features and on aetiological factors of our patients are summarised in Table 1. Moreover, liver chemistry tests are reported in Table 2.

Our patients did not show clinical symptoms or signs of thyroid dysfunction and did not receive medications that might have affected the radioimmunoassays performed in this study. As a control group 30 healthy subjects ( 23 men and seven women aged 25-73 years) were investigated.

Serum $T_{3},{ }^{11} T_{4},{ }^{12}$ thyrotropin ${ }^{13}$ and thyroxine binding globulin ${ }^{14}$ were determinated by standard radioimmunoassay methods. $T_{4} /$ thyroxine binding globulin and $T_{3} /$ thyroxine binding globulin ratios were calculated to give a free $\mathrm{T} 4$ and a free $T_{3}$ index. Thyroglobulin antibodies were evaluated by a radioassay procedure. ${ }^{15}$ Serum $\mathrm{FT}_{3}$ and $\mathrm{FT}_{4}$ were measured by direct radioimmunoassay with the

Table 1 Clinical diagnosis of our patients and aetiological factors

\begin{tabular}{lllll}
\hline & No. patients & Alcoholic & Postviral & Others \\
\hline $\begin{array}{l}\text { Chronic persistent } \\
\text { hepatitis }\end{array}$ & 2 & 0 & 2 & 0 \\
$\begin{array}{l}\text { Chronic active } \\
\text { hepatitis }\end{array}$ & 20 & 7 & 11 & $2^{*}$ \\
$\begin{array}{l}\text { Cirrhosis } \\
\text { * Cryptogenic }\end{array}$ & 33 & 19 & 9 & $5 \dagger$ \\
\hline $\begin{array}{l}\text { Two haemochromatosis and three cryptogenic } \\
\text { Two }\end{array}$
\end{tabular}

Table 2 Biochemical indices of liver function in 22 patients with chronic hepatitis and in 35 cirrhotics

\begin{tabular}{|c|c|c|c|c|}
\hline & $G O T$ & Bilirubin & Albumin & $\begin{array}{l}\text { Prothrombin } \\
\text { time }\end{array}$ \\
\hline $\begin{array}{l}\text { Chronic hepatitis } \\
\text { Cirrhosis }\end{array}$ & $\begin{array}{l}74 \cdot 5 \pm 17 \cdot 1 \\
30 \cdot 8 \pm 8 \cdot 4\end{array}$ & $\begin{array}{l}1 \cdot 3 \pm 0 \cdot 3 \\
2 \cdot 3 \pm 0 \cdot 6\end{array}$ & $\begin{array}{l}3 \cdot 6 \pm 0 \cdot 1 \\
2 \cdot 7 \pm 0 \cdot 1\end{array}$ & $\begin{array}{l}77 \cdot 6 \pm 3 \cdot 8 \\
50 \cdot 5 \pm 3 \cdot 2\end{array}$ \\
\hline
\end{tabular}

method of Romelli et al $^{16}$ by using a Lepetit kit (Milano). The thyrotropin releasing hormone test (200 $\mu \mathrm{g}$ intravenously) was performed in the morning, samples for thyrotropin determination being collected at $-15,0,20,30$ and 60 minutes.

The normal ranges in our laboratory for the above determinations are as follows: $\mathrm{T}_{3}, 80-200 \mathrm{ng} / \mathrm{dl} ; \mathrm{T}_{4}$, 4.5-12 $\mu \mathrm{g} / \mathrm{dl}$; thyroxine binding globulin, 18-32 $\mathrm{ng} / \mathrm{ml} ; \mathrm{T}_{3} /$ thyroxine binding globulin index, 3.4-9; $\mathrm{T}_{4}$ /thyroxine binding globulin index $(\times 10), 1 \cdot 8-4$; $\mathrm{FT}_{3}, 2.7-6.6 \mathrm{pg} / \mathrm{ml} ; \mathrm{FT}_{4}, 6.3-16.4 \mathrm{pg} / \mathrm{ml}$; basal thyrotropin, $<-5 \mu \mathrm{U} / \mathrm{ml}$ and maximum thyrotropin increase ( $\Delta$ thyrotropin) after thyrotropin releasing hormone, 5-25 $\mu \mathrm{U} / \mathrm{ml}$ for women and 3.5-15 $\mu \mathrm{U} / \mathrm{ml}$ for men.

The statistical analysis wa carried out using the Student's $t$ test and linear correlation as appropriate. Data are expressed as mean $\pm \mathrm{SF}$.

\section{Results}

The mean values for the different indices of thyroid function in the two groups of patients with liver disease and in normal controls are reported in Table 3. Cirrhotic patients showed significantly reduced serum levels of $T_{3}, T_{3} /$ thyroxine binding globulin ratio, $\mathrm{FT}_{3}, \mathrm{~T}_{4} /$ thyroxine binding globulin ratio and $\Delta$ thyrotropin and significantly increased levels of thyroxine binding globulin, $\mathrm{FT}_{4}$ and basal thyrotropin versus normals. Subjects with chronic hepatitis showed significantly lower $T_{3}$ /thyroxine binding globulin ratio and $\mathrm{FT}_{3}$ and higher thyroxine binding globulin and $\mathrm{FT}_{4}$ levels than in controls.

The comparison between the first and the second group of patients revealed that cirrhotics have significantly lower $T_{3}, T_{3} /$ thyroxine binding globulin ratio, $\mathrm{FT}_{3}, \mathrm{~T}_{4} /$ thyroxine binding globulin ratio and $\Delta$ thyrotropin. Antithyroglobulin antibodies were absent in all patients, but one with chronic alcoholic hepatitis and one with cirrhosis in whom high titres were present $(1: 10000)$; one of them (chronic alcoholic hepatitis) also had high serum thyrotropin concentrations $(14 \mu \mathrm{U} / \mathrm{ml})$ with exaggerated response to thyrotropin releasing hormone, with normal total and free $T_{3}$ and $T_{4}$, suggesting the coexistence of Hashimoto's thyroiditis and preclinical hypothyroidism. 
Table 3 Indices of thyroid function in patients with chronic liver disease (22 with chronic hepatitis, 33 with cirrhosis) and sex and age-matched healthy controls (mean $\pm S E$ ).

\begin{tabular}{|c|c|c|c|c|c|c|c|c|c|}
\hline & $\begin{array}{l}T_{3} \\
n g / d l\end{array}$ & $\begin{array}{l}T_{4} \\
\mu g / d l\end{array}$ & $\begin{array}{l}T B G \\
n g / m l\end{array}$ & $\begin{array}{l}T_{3} / T B G \\
\text { ratio }\end{array}$ & $\begin{array}{l}T / T B G \\
\text { ratio }(\times 10)\end{array}$ & $\begin{array}{l}F T_{3} \\
p g / m l\end{array}$ & $\begin{array}{l}F T_{4} \\
p g / m l\end{array}$ & $\begin{array}{l}\text { TSH } \\
\mu U / m l\end{array}$ & $\begin{array}{l}\Delta T S H \\
\mu U / m l\end{array}$ \\
\hline \multirow{3}{*}{$\begin{array}{l}\text { Chronic } \\
\text { hepatitis } \\
\text { Cirrhosis } \\
\text { Controls }\end{array}$} & $130 \pm 8 \cdot 2$ & $7 \cdot 5 \pm 0.5$ & $28.6 \pm 1.7 \dagger$ & $4 \cdot 67 \pm 0.51^{*}$ & $2 \cdot 84+0 \cdot 16$ & $3.6+0.2^{*}$ & $11.9+0.8^{*}$ & $2.7+0.2$ & $0.3+1.1$ \\
\hline & $78 \pm 5 \cdot 4 \ddagger \|$ & $6 \cdot 7 \pm 0 \cdot 4$ & $26 \cdot 5 \pm 1^{*}$ & $2 \cdot 99 \pm 0 \cdot 19+1$ & $2 \cdot 54 \pm 0 \cdot 10 \ddagger \S$ & $2 \cdot 9 \pm 0 \cdot 1 \neq \rrbracket$ & $11.9 \pm 0.5+$ & $3 \cdot 1 \pm 0 \cdot 2^{*}$ & $6 \cdot 4 \pm 0 \cdot 8+8$ \\
\hline & $140 \pm 6 \cdot 9$ & $7 \cdot 3 \pm 0 \cdot 2$ & $23 \cdot 7 \pm 0 \cdot 5$ & $5.97 \pm 0.28$ & $3.05 \pm 0.07$ & $4 \cdot 2 \pm 0 \cdot 1$ & $9 \cdot 9 \pm 0 \cdot 3$ & $2 \cdot 4 \pm 0 \cdot 1$ & $11 \cdot 1 \pm 1$ \\
\hline
\end{tabular}

${ }^{*} \mathrm{p}<0.05$ vs controls; $\dagger \mathrm{p}<0.01$ vs controls; $\ddagger \mathrm{p}<0.001$ vs controls; $\S \mathrm{p}<0.05$ vs chronic hepatitis; | $\mathrm{p}<0.01$ vs chronic hepatitis;

$\| \mathrm{p}<0.001$ vs chronic hepatitis.

The results obtained with total and free $T_{3}$ and $T_{4}$ concentrations in the individual patients are shown in Figs. 1-3. Low $T_{3}$ values were observed in 18 cirrhotics and in two patients with chronic hepatitis. $\mathrm{T}_{4}$ was normal in all cases, except for five cirrhotics with low values and one subject for each group with slightly raised concentrations (Fig. 1). $\mathrm{FT}_{3}$ was reduced in 18 cirrhotics and in four subjects with hepatitis (Fig. 2). $\mathrm{FT}_{4}$ was normal in all instances except two cases with low, and four with raised concentrations (Fig. 3). Figure 4 shows that almost all patients with low $\mathrm{FT}_{3}$ had normal or sometimes raised $\mathrm{FT}_{4}$.

$\mathrm{T}_{3}$ /thyroxine binding globulin and $\mathrm{T}_{4}$ /thyroxine binding globulin ratios were significantly correlated with the actual $\mathrm{FT}_{3}$ and $\mathrm{FT}_{4}$ concentrations, respectively, both in subjects with cirrhosis and chronic hepatitis (Figs. 5, 6). While the correlation coefficient, however, between $\mathrm{T}_{3}$ /thyroxine binding

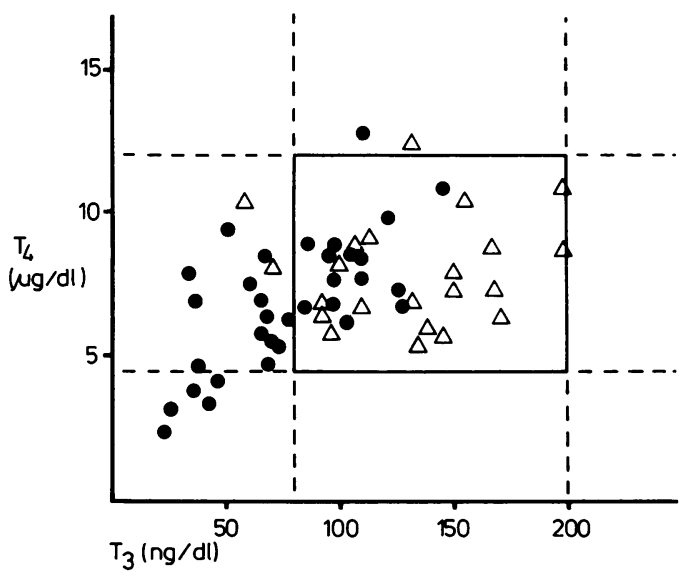

Fig. 1 Serum $T_{4}$ vs $T_{3}$ concentrations in individual patients with liver cirrhosis $(\bullet)$ and chronic hepatitis $(\Delta)$. Solid lines outline normal range. globulin ratio and $\mathrm{FT}_{3}$ was not different from that observed in normal controls $(r=0.65, p<0.001)$, the coefficients between $T_{4}$ /thyroxine binding globulin ratio and $\mathrm{FT}_{4}$ were lower, particularly in cirrhotics, than that observed in normals $(\mathrm{r}=0.82, \mathrm{p}<0.001)$. Basal serum thyrotropin concentrations above the normal range were found in two cirrhotic patients $(6.5$ and $7.8 \mu \mathrm{U} / \mathrm{ml})$ and in the above mentioned subject with chronic hepatitis and Hashimoto's thyroiditis. The thyrotropin response to thyrotropin releasing hormone was normal in 23 and impaired in 10 patients with cirrhosis; among subjects with chronic hepatitis 18 had normal, two impaired and two exaggerated responses. The delayed pattern of thyrotropin response to thyrotropin releasing hormone - that is, 60 minute concentrations higher than 20 minute concentrations, was observed in eight cirrhotics.

Simple correlation analysis showed that serum $T_{3}$

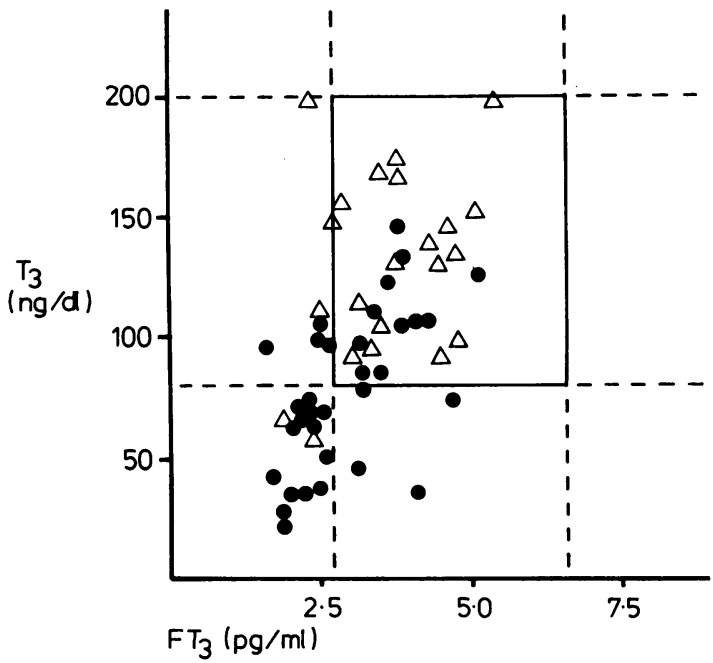

Fig. 2 Serum $\mathrm{T}_{3}$ vs $\mathrm{FT}_{3}$ concentrations in patients with cirrhosis and chronic hepatitis. Symbols as in Fig. 1. 


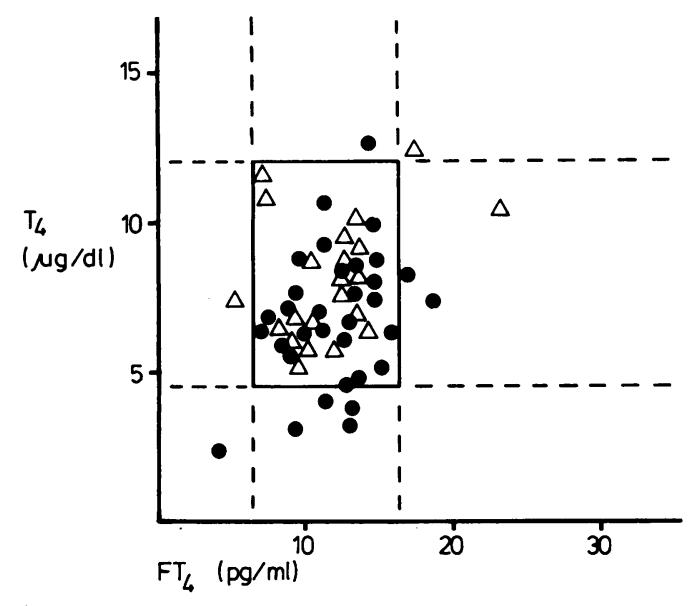

Fig. 3 Serum $T_{4}$ vs $F T_{4}$ concentrations in patients with cirrhosis and chronic hepatitis. Symbols as in Fig. 1 .

concentration was significantly correlated in both patient groups with serum bilirubin albumin, and prothrombin time, but not with transaminases.

\section{Discussion}

The existence of the so called low $T_{3}$ syndrome that is, low total $T_{3}$ with normal total $T_{4}$ and

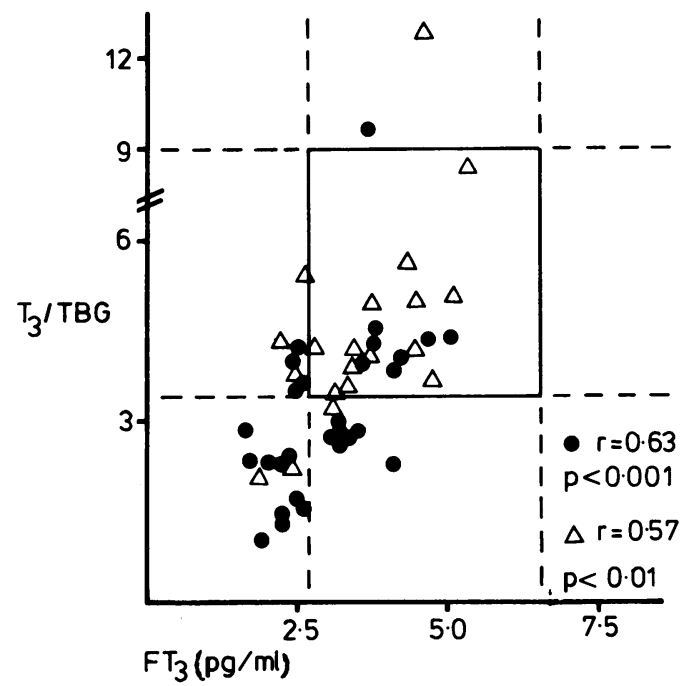

Fig. $5 T_{3} / T B G$ ratios vs $F T_{3}$ values in patients with cirrhosis and chronic hepatitis. Symbols as in Fig. 1.

thyrotropin concentrations in the absence of clinical hypothyroidism, has been frequently reported in patients with chronic liver disease as well as in many other non-thyroidal illnesses, ${ }^{1-36} 17$ and it has been shown to depend on impaired liver conversion of $T_{4}$ to $\mathrm{T}_{3}{ }^{2}$

Our data also confirm a highly significant reduction of $T_{3}$ serum concentration in liver disease, the

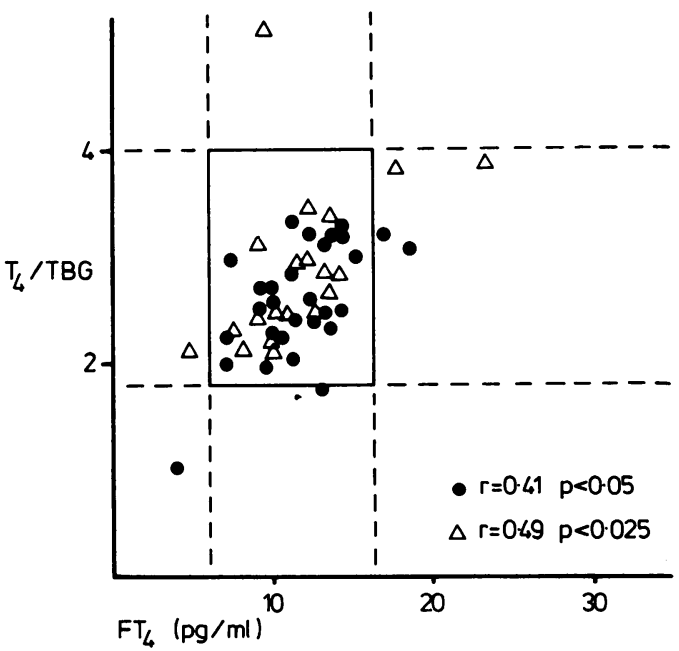

Fig. $6 T_{4} / T B G$ ratios vs $F T_{4}$ values in patients with cirrhosis and chronic hepatitis. Symbols as in Fig. 1.
Fig. 4 Serum $F T_{4}$ vs $F T_{3}$ concentrations in patients with cirrhosis and chronic hepatitis. Symbols as in Fig. 1. 
lowest values being found in cirrhotics, with generally normal total $\mathrm{T}_{4}$ and thyrotropin concentrations.

In a large group of alcoholic patients Israel et $a^{9}$ reported a significant inverse correlation between serum $T_{3}$ concentrations and the severity of liver dysfunction as well as a progressive $T_{3}$ increase in those subjects eventually displaying a favourable outcome, suggesting that $T_{3}$ concentrations in patients with advanced liver disease may be considered as a helpful prognostic indicator. Moreover, we have found a good correlation between $T_{3}$ concentrations and serum albumin, bilirubin, and prothrombin-time, while no correlation has been found with the hepatic inflammatory indices like the transaminases and $\gamma$ globulins. These results suggest that $T_{3}$ concentrations should be considered a sensitive index of hepatic function in liver disease.

Only little data have been previously reported on direct measurement of free thyroid hormones in liver patients. Green $e t a l^{3}$ found normal $\mathrm{FT}_{3}$ and $\mathrm{FT}_{4}$ in a small group of cirrhotic patients while low $\mathrm{FT}_{4}$ and normal $\mathrm{FT}_{3}$ concentrations were present in alcoholic fatty liver. Many studies performed with equilibrium dialysis, however, showed decreased $\mathrm{FT}_{3}$ and normal or frequently increased $\mathrm{FT}_{4}$ concentrations. ${ }^{218}$ These findings are confirmed by the present study with direct radioimmunoassay of $\mathrm{FT}_{3}$ and $\mathrm{FT}_{4}$, both in cirrhotics and in chronic hepatitis patients, although showing more severe abnormalities, especially lower $\mathrm{FT}_{3}$ concentrations in the former group. These data suggest that in chronic liver disease euthyroidism is maintained by a subtle equilibrium between low $\mathrm{FT}_{3}$ and raised $\mathrm{FT}_{4}$ concentrations. The reason for the discrepancy between normal total $\mathrm{T}_{4}$ and increased $\mathrm{FT}_{4}$ concentrations in liver disease is unclear. The finding of increased, rather than decreased, thyroxine binding globulin serum concentration in our patients, in agreement with other reports, ${ }^{19} 20$ as well as the finding of a reduced $\mathrm{T}_{4} /$ thyroxine binding globulin ratio with an increased $\mathrm{FT}_{4}$ concentration is in agreement with previous suggestions for the presence of a circulating inhibitor (perhaps a IgM molecule) of $\mathrm{T}_{4}$ binding to thyroxine binding globulin in non-thyroidal illnesses including liver cirrhosis. $^{78}$ Although we have found a significant correlation between $\mathrm{T}_{4}$ /thyroxine binding globulin ratio and $\mathrm{FT}_{4}$ in our patients, the correlation coefficient was significantly lower than in normal controls, a finding compatible with the above hypothesis. Slightly increased serum thyrotropin concentration in liver cirrhosis has been previously reported, ${ }^{2}{ }^{3}$ but the possibility that this finding indicates the existence of hypothyroidism is unlikely in view of the normal or even reduced thyrotropin response to thyrotropin releasing hormone, ${ }^{3}$ a finding confirmed in the present investigation. More likely, the abnormalities in thyrotropin secretion reflect the existence of hypothalamic-pituitary dysfunction in advanced liver disease. In particular, several lines of evidence suggest a reduced dopaminergic tone as a consequence of the accumulation of false neurotransmitters, ${ }^{21}{ }^{22}$ which might be responsible for raised basal thyrotropin concentrations, as dopamine has been shown to exert an inhibitory effect in the regulation of thyrotropin secretion. ${ }^{23}$ True evidence for hypothyroidism, albeit at a preclinical stage, as suggested by clearly raised thyrotropin concentrations and increased thyrotropin releasing hormone response, has been only found in one patient of the present series, who was affected with Hashimoto's thyroiditis and severe alcoholic hepatitis. Only one of the other 54 patients with either liver cirrhosis or chronic hepatitis had high titres of thyroglobulin antibodies suggesting Hashimoto's thyroiditis, while this disease is relatively frequent in primary biliary cirrhosis and in autoimmune hepatitis. ${ }^{24}$ In this connection it is to be pointed out that none of these two patients had positive tests for antinuclear, antismooth muscle and antimithocondrial antibodies.

In conclusion, the present investigation, in which thyroid function has been evaluated with all the clinically available indices, confirms the existence of several abnormalities in thyroid function tests in chronic liver disease, although showing that euthyroidism is maintained virtually in all patients, probably as a result of low-normal $\mathrm{FT}_{3}$ and highnormal $\mathrm{FT}_{4}$. Furthermore, $\mathrm{T}_{3}$ serum concentrations appear to parallel the severity of liver dysfunction.

\section{References}

1 Chopra IJ, Solomon DH, Chopra U, Young RT, Chuateco GN. Alterations in circulating thyroid hormones in hepatic cirrhosis; evidence for euthyroidism despite subnormal serum triiodothyronine. $J$ Clin Endocrinol Metab 1974; 39: 501-11.

2 Nomura S, Pittman CS, Chambers JB, Buck MW, Shimizu T. Reduced peripheral conversion of thyroxine to triiodothyronine in patients with hepatic cirrhosis. $J$ Clin Invest 1975; 56: 643-52.

3 Green JRB, Snitcher EJ, Mowat NAG, Ekins RP, Rees LH, Dawson AM. Thyroid function and thyroid regulation in euthyroid men with chronic liver disease: evidence of multiple abnormalities. Clin Endocrinol 1977; 7: 453-61.

4 Walfish PG, Orrego H, Israel Y, Blake, J Kalant H. 
Serum triiodothyronine and other clinical and laboratory indices of alcoholic liver disease. Ann Intern Med 1979; 91: 13-6.

5 Geurts J, Demeester-Mirkine N, Glinoer D, Prigogine $\mathrm{T}$, Fernandez Deuille M, Corvilain J. Alterations in circulating thyroid hormones and thyroxine binding globulin in chronic alcoholism. Clin Endocrinol 1981; 14: 113-8.

6 Chopra IJ, Solomon DH, Hepner GW, Morgestein AA. Misleadingly low free thyroxine index and usefulnesses. Ann Intern Med 1979; 90: 905-12.

7 Woeber KA, Maddux BA. Thyroid hormone binding in nonthyroid illness. Metabolism 1981; 30: 412-6.

8 Chopra IJ, Chuateco GN, Nguyen AH, Solomon D. In search of an inhibitor of thyroid hormone binding to serum proteins in nonthyroid illnesses. $J$ Clin Endocrinol Metab 1979; 49: 63-9.

9 Israel Y, Walfish PG, Orrego H, Blake J, Kalant H. Thyroid hormones in alcoholic liver disease: effect of treatment with 6-propylthiouracil. Gastroenterology 1979; 76: 116-22.

10 Leevy CM, Popper H, Sherlock S. Hepatitis. In: Diseases of the liver and biliary tract. Standardization of nomenclature. Diagnostic criteria and diagnostic methodology. London: Castle House Publications, 1979; 1-11.

11 Larsen PR. Direct immunoassay of triiodothyronine in human serum. J Clin Invest 1972; 51: 1939-45.

12 Modder G, Sokolowski G. Ein Test zur radioimmunologischen Bestimmung des Gesamtthyroxin in Serum mit Hilfe der Solid-Phase-Technik. Nuc Compact 1978; 3: 117-20.

13 Odell WD, Rayford PL, Ross GT. Simplified, partially automated, method for radioimmunoassay of human thyroid-stimulating, growth, luteinizing and folliclestimulating hormones. J Lab Clin Med 1967; 70: 973-80.

14 Levy RP, Marshall JS, Velayo NL. Radioimmunoassay of human thyroxine-binding globulin (TBG). J Clin Endocrinol Metab 1971; 32: 372.
15 Bodlander P, Anjonilla JR, Twomey SL. Sensitive radioimmunological screening test for antithyroglubulin auto-antibodies. Clin Chem 1978; 24: 2-6.

16 Romelli PB, Pennisi F, Vancheri L. Measurement of free thyroid hormones in serum by column absorption chromatography and radioimmunoassay. $J$ Endocrinol Invest 1979; 2: 25-40.

17 Berowdel F, Surks MI, Oppenheimer JH. High incidence of decreased serum triiodothyronine concentration in patients with non-thyroidal disease. $J$ Clin Endocrinol Metab 1975; 41: 27-40.

18 Hepner GW, Chopra IJ. Serum thyroid hormone levels in patients with liver disease. Arch Intern Med 1979; 139: 1117-20.

19 Schussler GC, Scheffner F, Korn F. Increased serum thyroid hormone binding and decreased free hormone in chronic active liver disease. $N$ Engl J Med 1978; 299: $510-4$.

20 L'Age $M$, Wenzel $M$, Schleusener $H$. Relations between serum levels of TSH, TBG, $\mathrm{T}_{4}, \mathrm{~T}_{3}, \mathrm{rT}_{3}$ and various histologically classified chronic liver diseases. $J$ Endocrinol Invest 1980; 4: 379-83.

21 Fischer JE, Baldessarini RJ. False neurotransmitters and hepatic failure. Lancet 1971; 2: 75-80.

22 Borzio M, Caldara R, Ferrari C, Barbieri C, Borzio F, Romussi M. Growth hormone and prolactin secretion in liver cirrhosis: evidence for dopaminergic dysfunction. Acta Endocrinol 1981; 97: 441-7.

23 Scanlon MF, Pourmand M, Mcgregor AM, RodriguezAznao AM, Hall K, Gomez-Pan A, Hall R. Some current aspects of clinical and experimental neuroendocrinology with particular reference to growth hormone, thyrotropin and prolactin. $J$ Endocrinol Invest 1979; 2: 307-31.

24 Crowe JP, Christensen E, Butler J, Wheeler P, Doniach D, Keenan J, Williams R. Primary biliary cirrhosis: the prevalence of hypothyroidism and its relationship to thyroid autoantibodies and sicca syndrome. Gastroenterology 1980; 78: 1437-41. 